\title{
Green Synthesis of Copper Nano-Particles Using Asparagus adscendens Roxb. Root and Leaf Extract and Their Antimicrobial Activities
}

\author{
Sapna Thakur ${ }^{1 *}$, Sushma Sharma ${ }^{2}$, Shweta Thakur ${ }^{3}$ and Radheshyam Rai ${ }^{4}$ \\ ${ }^{1}$ Department of Biotechnology, ${ }^{2}$ Department of Agriculture, Akal College of Agriculture, \\ Eternal University, Himachal Pradesh, India \\ ${ }^{3}$ Department of Physics, University of Aveiro, 3810-193 Aveiro, Portugal \\ ${ }^{4}$ Department of Physics, Eternal University, Himachal Pradesh, India
}

*Corresponding author

\begin{tabular}{|l|}
\hline Ke y w o r d s \\
Green synthesis, \\
Copper nanoparticals, \\
Asparagus adscendens \\
Roxb.
\end{tabular}

A B S T R A C T
Bio-nanotechnology has provides extensive research with emergence in biotechnology and nanotechnology which synthesize nanoparticles using bio-organisms like plant parts, bacteria yeasts, algae and fungi and that is more compatible with the green chemistry principles. Copper nanoparticles were biologically synthesized by using the root extract and leaf extract of Asparagus adscendens Roxb. as a reducing agent. By treatment of aqueous solutions of $\mathrm{CuSO}_{4} \cdot 5 \mathrm{H}_{2} \mathrm{O}$ with root and leaf extract stable copper nanoparticles were formed. UV-Visible study revealed quantitative formation of copper nanoparticles or characteristic absorption peak of $\mathrm{Cu}$ nano-particles in both cases at the range of 500$700 \mathrm{~nm}$. These biosynthesized $\mathrm{Cu}$ nanoparticles were characterized with the help of Fourier transform infrared spectroscopy (FTIR) and High Resolution Transmission Electron Microscopy (HRTEM). The involvement of proteins and possible reducing agent was confirmed by FTIR analysis. HRTEM confirms the formation and the crystalline nature of copper nanomaterial. Thus, this method can be used as a rapid and environmental friendly, non-toxic and safe biological reagents approach for copper nanoparticles synthesis. The copper nanoparticles were isolated from these herbal roots and leaves tested for antimicrobial activity. The test cultures included in this study were Escherichia coli, Bacillus subtilis, Salmonella typhi, Klebsiella pneumonia, and Staphylococcus aureus. This study scientifically revealed significant zone of inhibition against such pathogenic bacteria's which has many pharmaceutical applications for the control of deadly pathogens.

\section{Introduction}

In recent years nanotechnology has provided extensive research with emergence in Physics, Chemistry, Engineering, Biotechnology, Food-technology, Medical sciences and forming impact on all forms of life with an important aspect due to its innumerable applications (Baker and Satish 2012). The prefix nano means a billionth $\left(1 \times 10^{-9}\right)$ and nanotechnology is a field of science which deals with production and manipulation of 
metal nanoparticles which are of interest because of their unique optical, electronic and magnetic properties. The nanoparticles of transition metals are an important class of semiconductors, which have expressed significant advances owing to wide range of applications in the field of electronics, sensors, automobiles, nano-fabrics, bio-medical, agriculture, bio-engineering, medicines, and other areas (Ramgir et al., 2013). A wide range of copper nanoparticles can be produced using chemical methods and physical methods. Usually microemulsion (colloidal) techniques (Panigrahi et al., 2006), sonochemical reduction (Song et al., 2004), electrochemical (Zhong et al., 2008), microwave-assisted (Kapoor and Mukherjee 2003), and hydrothermal (Huang et al., 1997) syntheses are the main techniques for the synthesis of nanoparticles through the chemical approach. Physical methods for nanoparticles synthesis are laser (pulse) ablation (Zhang et al., 2007), vacuum vapor deposition (Lisiecki and Pileni 1993), pulsed wire discharge (PWD) (Tanori and Pileni 1997) and mechanical milling (Wu and Chen 2004).

These chemical or physical methods for the synthesis of copper nanoparticles are suffering with various limitations such as expensive reagents, generation of hazardous toxic chemicals, and tedious process to isolate nanoparticles etc. Hence, upsurge the researchers to develop new methods for the synthesis of nanoparticles which should be required inexpensive reagent, develop safe as well as less drastic reaction condition and eco-friendly alternative approaches. Synthesis using bioorganisms is compatible with the green chemistry principles. "Green synthesis" of nanoparticles makes use of environmental friendly, non-toxic and safe reagents (Salam et al., 2012). If the exact mechanism of biological synthesis is explained, it could offer an extra advantage over the chemical methods by means of higher productivity and lower cost. In biosynthesis of nanoparticles the oxidation/reduction is the main reaction that occurs during the production of nanoparticles. Metal compounds usually reduce into their respective nanoparticles because of proteins, enzymes and the phytochemicals with antioxidant or reducing properties present in plant extracts. Copper nanostructures have been demonstrated to possess properties useful for applications in gas sensing (Zhang et al., 2007), CO oxidation (White et al., 2006), Photo catalysis (Kuo et al., 2007), (Ho and Huang 2009), (Kuo and Huang 2008; Xu et al., 2006; Yu et al., 2007), photochemical evolution of $\mathrm{H}_{2}$ from water (Yang et al., 2008), photocurrent generation and organic synthesis (Altman et al., 2007; McShane and Choi 2009).

Review of literature revealed that biologically synthesized copper nanoparticles using plants extract has been unexplored; Synthesis of copper nano particles using protein solution with copper sulphate solution was done and reduced the solution with sodium borohydrate. Argon gas was used as inert medium during the process to avoid oxidation (EstebanCubillo etal., 2006). Synthesis of $\mathrm{Cu}_{2} \mathrm{O}$ nanoparticles using Tridax procumbens leaf extract was reported and water-soluble carbohydrates present in the plant materials were mainly responsible for the reduction of copper ions to nano-sized $\mathrm{Cu}_{2} \mathrm{O}$ particles. By taking Escherichia coli as a model for Gramnegative bacteria, which always causes a variety of suppurative infections and toxinoses in humans, as a model bio-particle, the negative bio-effect of nano- $\mathrm{Cu}_{2} \mathrm{O}$ on $E$. coli cells was evaluated by disc diffusion method (Gopalakrishnan et al., 2012). A novel biological approach for the formation of copper nanoparticles using Clove extract has been done. X-Ray diffraction pattern reveals the formation of $\mathrm{Cu}$ nanoparticles, which shows crystalline structure. Transmission 
electron microscopy suggested particles size and shape in the range of 5-40 $\mathrm{nm}$. Scanning electron microscopy image reveals that the particles are of spherical and granular nature (Subhankari and Nayak 2013).Copper nanoparticles were biologically synthesized using Magnolia leaf extract as reducing agent. UV-vis spectroscopy, TEM and SEM was used to monitor the quantitative formation of copper nanoparticles which indicated that they ranged in size from 40 to $100 \mathrm{~nm}$ and copper nanoparticles shows antibacterial activity against Escherichia coli bacteria (Lee et al., 2011). The plants Asparagus adscendens, Bacopa monnieri, Ocimum bacilicum, and Withania somnifera were used and compared for their extracellular synthesis of metallic copper nanoparticles (CuNPs) (Sapna Thakur 2014).

Hence the present study was carried out to synthesize and characterize the copper nanoparticles using Asparagus adscendens Roxb root and leaf extract at room temperature and its antibacterial activity against pathogenic bacteria's.

\section{Plant description}

Asparagus adscendens Roxb. (Shatavari) is a flowering perennial plant species in the genus Asparagus (Grubben 2004). It is initially grown in thick forest in natural form, and is a customary medicinal plant (Fig. 1 $\mathrm{A} \& \mathrm{~B})$. The plant is a source of a nutritious starch and low in calories and is very low in sodium. It is a good source of vitamin also. The shoots are prepared and served in a number of ways around the world, typically as an appetizer. The part of the plant that is used in medicines is not specified but is mostly to be the root. Active compounds present in asparagus are well known for their multiple health benefits. The powdered dried root exhibits galactogogic properties. It is reported to be useful against diarrhoea, dysentery and in general debility (Chopra and Chopra, 2006; Kirtikar and Basu 1918). Some steroidal saponins, glycosides were reported from fruits, roots (Sharma and Sharma 1984)and leaves (Sharma et al., 1982) and several lipid constituents has identified from the roots (Tandon et al., 1990).

\section{Materials and Methods}

\section{Preparation of Leaf extracts}

The synthesis of copper nanoparticles has been carried out using the root and leaf extract of Asparagus adscendens. The plant of Asparagus adscendens were collected from the Bhajol, Solan, Himachal Pradesh. The healthy and matured root and leaves were selected, washed thoroughly. The epidermis of roots was peeled off with the help of a scalpel and the pith was separated with the help of forceps to get the cortex. $5 \mathrm{~g}$ of cortex was homogenized in a mortar and Pestle and suspended in $100 \mathrm{ml}$ of distilled water. On the other hand $5 \mathrm{~g}$ of leaves chopped and suspended in $100 \mathrm{ml}$ of distilled water. Then both the solutions were boiled up to $10 \mathrm{~min}$ at $110^{\circ} \mathrm{C}$ in a glass flask. The suspended mass was then filtered out; the filtrate obtained contains the bioactive components leached from the roots and leaves. This filtrate was used as the extract for the preparation of copper nanoparticles.

\section{Synthesis of copper nanoparticles}

In the separate experiments to the $10 \mathrm{ml}$ of root extract and $10 \mathrm{ml}$ of leaf extract, $100 \mathrm{ml}$ of $1 \mathrm{mM}$ copper salt $\left(\mathrm{CuSO}_{4} \cdot 5 \mathrm{H}_{2} \mathrm{O}\right)$ purchased from Hi Media India Ltd. solution was added drop wise. Similarly, two control samples, in one plant extract and in another solution of copper sulphate were also maintained (Fig. $2 A \& B)$. The reaction mixtures along with controls were exposed to room temperature for $1 \mathrm{hr}$ under static condition the change in color 
was noted from pale yellow to sky blue in case of root extract and in case of leaf extract brown to sea green. Thus color change indicates reduction and reduced copper nanoparticles were obtained and monitored by the UV-visible spectral analysis. Schematic illustration of synthesis mechanism of CuNPs from Asparagus adscendens extracts and $1 \mathrm{Mm}$ $\mathrm{CuSO}_{4}$ showns in figure 3 .

\section{UV-Visible spectroscopy studies}

The bio reduction of copper sulphate ions in to copper nanoparticles in the root extract and leaf extract was monitored by UV-Vis spectrum the most confirmatory tool for the detection of surface Plasmon resonance property (SPR) of copper nanoparticles, by sampling aliquots of the reaction mixture. The aliquots were diluted with double distilled water and spectrum of diluted solution recorded using UV-Visible spectrophotometer [Model- Shimadzu UV 1800] in the wavelength range $300-800 \mathrm{~nm}$. Baseline correction was made with double distilled water.

\section{Refining of sample}

The completely copper nanoparticles were then concentrated by repetitive centrifugation and re-suspension using cold centrifuge [Eppendorf; Model-R5210] compared at $14,000 \mathrm{rpm}$ for $15 \mathrm{~min}$. The pellet was washed and re-dispersed thrice in double distilled water to make copper nanoparticles free from biochemical constituents.

\section{FTIR observations}

Samples of the aqueous solution of the copper nanoparticles were prepared by using centrifugation and analyses done by FTIR. Samples were measured by Bruker Tensor 27 FTIR spectrometer in attenuated total reflection mode (Pike Technologies, Gladi ATR for FTIR with diamond crystal) and using spectral range of $4000-600 \mathrm{~cm}^{-1}$. The FTIR spectra of root and leaf extracts taken after synthesis of copper nanoparticles were analyzed which was discussed for the possible function groups for the formation of copper nanoparticles.

\section{Transmission electron microscopy (TEM) and selected area electron diffraction measurements (SEAD)}

Samples for TEM were prepared by loading a drop of the refined nanoparticle solution on the carbon coated copper grid followed by drying under Infrared light for $30 \mathrm{~min}$.

TEM and SAED measurements were then performed on instrument operated at an accelerating voltage of $200 \mathrm{Kv}$ (Philips; Model CM 200).

\section{Antibacterial screening}

The antibacterial activities of copper nanoparticles were studied by agar well diffusion method against Gram negative bacteria Pseudomonas aeruginosa, Escherichia coli and Gram positive bacteria Bacillus subtilis, Staphylococcus aureus. The bacterial cultures were obtained from Department of Microbiology, School of Biotechnology, Shoolini University, Solan, Himachal Pradesh, India.

Bacterial strains grown on nutrient agar at $37^{\circ} \mathrm{C}$ for $18 \mathrm{hr}$ were suspended in a saline solution $(0.85 \% \mathrm{NaCl})$ and adjusted to a turbidity of 0.5 MacFarland standard $\left(10^{8}\right.$ $\mathrm{CFU} / \mathrm{ml}$ ).

Mueller-Hinton agar media was used to perform sensitivity assay (Wagner 1996)and the diameter of zone of inhibition produced by the extract compared with those produced by the commercial control antibiotics Ampicillin $(25 \mu \mathrm{g} / \mathrm{ml})$. 


\section{Results and Discussion}

\section{UV-visible spectroscopy}

Samples of the reaction mixture were diluted with double distilled water and then subjected to the spectral measurement. After mixing the solution of copper sulphate with aqueous leaf extract, the reaction mixture change rapidly from light brown to see green color and in case of root extract the reaction mixture changed from pale yellow to sky blue color. The new color was ascribed to the excitation of surface plasmon vibrations in the copper nanoparticles, which indicates the formation of copper nanoparticles directly and (Fig. 4A\&B) shows the absorption spectra of reaction mixtures of leaf extract androot extract containing copper nanoparticle solution after $1 \mathrm{hr}, 16 \mathrm{hr}, 24 \mathrm{hr}$ and $40 \mathrm{hr}$ respectively. After the reduction, the absorption maxima observed in both cases of copper nanoparticles solution at 500 to 700 $\mathrm{nm}$ range wavelength. It is evident that the ions of copper sulphate in both cases are reduced to copper nanoparticles.

\section{FTIR analysis}

The analysis of IR spectra gives an idea about biomolecules bearing different functionalities which are present in underlying system. The (FTIR) Fourier transform infrared spectroscopy spectra of root and leaf extracts containing copper nanoparticles are illustrated (Fig. 5 A\&B); (Table 1). Comparison between spectra of leaf extract solution and root extract solution of Asparagus adscendens reveals few changes in the positions as well as on the magnitude of the absorption bands. The spectra of leaf extract and copper nanoparticles solution shows the presence of multiple bands at 3320, 2950, 2460, 2180, 1860 and $1637 \mathrm{~cm}^{-1}$ which clearly demonstrates the amide group at band 3320 $\mathrm{cm}^{-1}$, and alkanes at $2950 \mathrm{~cm}^{-1}$ whereas carboxlic acid group at $2460 \mathrm{~cm}^{-1}$ and alkynes at band $2180 \mathrm{~cm}^{-1}$, and anhydride group present at $1860 \mathrm{~cm}^{-1}$, and the band at $1640 \mathrm{~cm}^{-}$ 1 can be assigned to the amide I band. Therefore it appears more likely that the reduction of copper ions and stabilization of synthesized copper nanoparticles is the responsibility of many functional groups, including amines, alcohols, ketones, aldehydes, alkenes and carboxylic acids, that are present in plant metabolites and reducing sugars. On the other hand the FTIR spectrum of the root extract and copper nanoparticles solution showed bands at 1720, 3030 and 3450 $\mathrm{cm}^{-1}$. The intense band absorbance at $3450 \mathrm{~cm}^{-}$ ${ }^{1}$ is the characteristic of the amine functional group and aromatic compounds and the band at $3030 \mathrm{~cm}^{-1}$ can be assigned to the carboxylic acid $(\mathrm{O}-\mathrm{H})$ band of the proteins released by the Asparagus root. In addition some bands centred at $1720 \mathrm{~cm}^{-1}$ characteristic to the carboxylic acid $(\mathrm{C}=\mathrm{O})$ band also indicates a small concentration of protein in the root extract and copper nanoparticles solution. Thus it is obvious that bands are assigning to the carbonyl groups and secondary amines, are surrounded by some proteins and metabolites having functional groups of amines, alcohols, phenols, ketones, aldehydes, and carboxylic acids.

\section{High resolution transmission electron microscopy (HRTEM)}

The microstructures and size of the biosynthesized copper nanoparticles were studied by HRTEM (High Resolution Transmission Electron Microscopy) analysis. The typical HRTEM images of the copper nanoparticles synthesized by Asparagus adscendens leaf extract as reducing agent is shown (Fig. 6) the micrograph formation of spherical-shaped particles in the range of 10$15 \mathrm{~nm}$ at $20 \mathrm{~nm}$ scale and the insets show the facets. The size is not homogeneous and they are broadly distributed. 
Table.1 Correlation chart of FTIR frequencies

\begin{tabular}{|c|c|c|c|c|}
\hline S. No. & Frequency $\left(\mathrm{cm}^{-1}\right)$ & Type of vibrations & Bond present & Intensity \\
\hline \multicolumn{5}{|l|}{ Leaf } \\
\hline 1. & 3320 & Alcohols & $\mathrm{O}-\mathrm{H}$ & $\mathrm{m}$ \\
\hline 2. & 2950 & Alkanes & $\mathrm{C}-\mathrm{H}$ & $\mathrm{m}$ \\
\hline 3. & 2460 & Carboxlic acid & $\mathrm{O}-\mathrm{H}$ & $\mathrm{m}$ \\
\hline 4. & 2180 & Alkyne & $\mathrm{C}=\mathrm{C}$ & $\mathrm{m}-\mathrm{w}$ \\
\hline 5. & 1860 & Anhydride & $\mathrm{C}=\mathrm{O}$ & S \\
\hline 6. & 1637 & Amide & $\mathrm{C}=\mathrm{O}$ & S \\
\hline \multicolumn{5}{|l|}{ Root } \\
\hline 1. & 3450 & Amine & $\mathrm{N}-\mathrm{H}$ & $\mathrm{s}$ \\
\hline 2. & 3030 & Carboxlic acid & $\mathrm{O}-\mathrm{H}$ & bond $\mathrm{v}$ \\
\hline 3. & 1720 & Carboxlic acid & $\mathrm{C}=\mathrm{O}$ & $\mathrm{S}$ \\
\hline
\end{tabular}

Table.2 Antibacterial activity of copper nanoparticles synthesized from Asparagus adscendens roots and leaves extract

\begin{tabular}{|c|c|c|c|c|c|c|c|}
\hline \multirow{3}{*}{ Microorganism } & \multicolumn{7}{|c|}{ Zone of inhibition in $\mathrm{mm}$} \\
\hline & \multirow{2}{*}{$\begin{array}{c}10 \mu \mathrm{l} \text { of } \\
1 \mathrm{mM} \\
\mathrm{CuSO}_{4}\end{array}$} & \multirow{2}{*}{$\begin{array}{l}10 \mu \mathrm{l} \text { of } \\
\text { plant } \\
\text { leaf ext. }\end{array}$} & \multirow{2}{*}{$\begin{array}{l}10 \mu \mathrm{l} \text { of } \\
\text { plant } \\
\text { root ext. }\end{array}$} & \multicolumn{2}{|c|}{$10 \mu \mathrm{l}$ of $\mathrm{Cu}$ NPs } & \multirow{2}{*}{$\begin{array}{l}20 \mu \mathrm{g} / \mathrm{ml} \text { of } \\
\text { Ampicillin }\end{array}$} & \multirow{2}{*}{$\begin{array}{l}20 \mu \mathrm{g} / \mathrm{ml} \text { of } \\
\text { streptomycin }\end{array}$} \\
\hline & & & & leaf ext. & root ext. & & \\
\hline E.coli & 7 & 2 & 3 & 19 & 20 & 14 & 12 \\
\hline Bacillus subtilis & 6 & 4 & 4 & 17 & 18 & 12 & 11 \\
\hline Salmonella typhi & - & - & - & 19 & 21 & 14 & 13 \\
\hline Klebsiella pneumonia & - & - & - & 18 & 18 & 13 & 11 \\
\hline Staphylococcus aureus & 5 & 2 & 4 & 16 & 17 & 12 & 11 \\
\hline
\end{tabular}

Ec Escherichia coli; Bs Bacillus subtilis; St Salmonella typhi; Kp Klebsiella pneumonia; Sa Staphylococcus aureus.

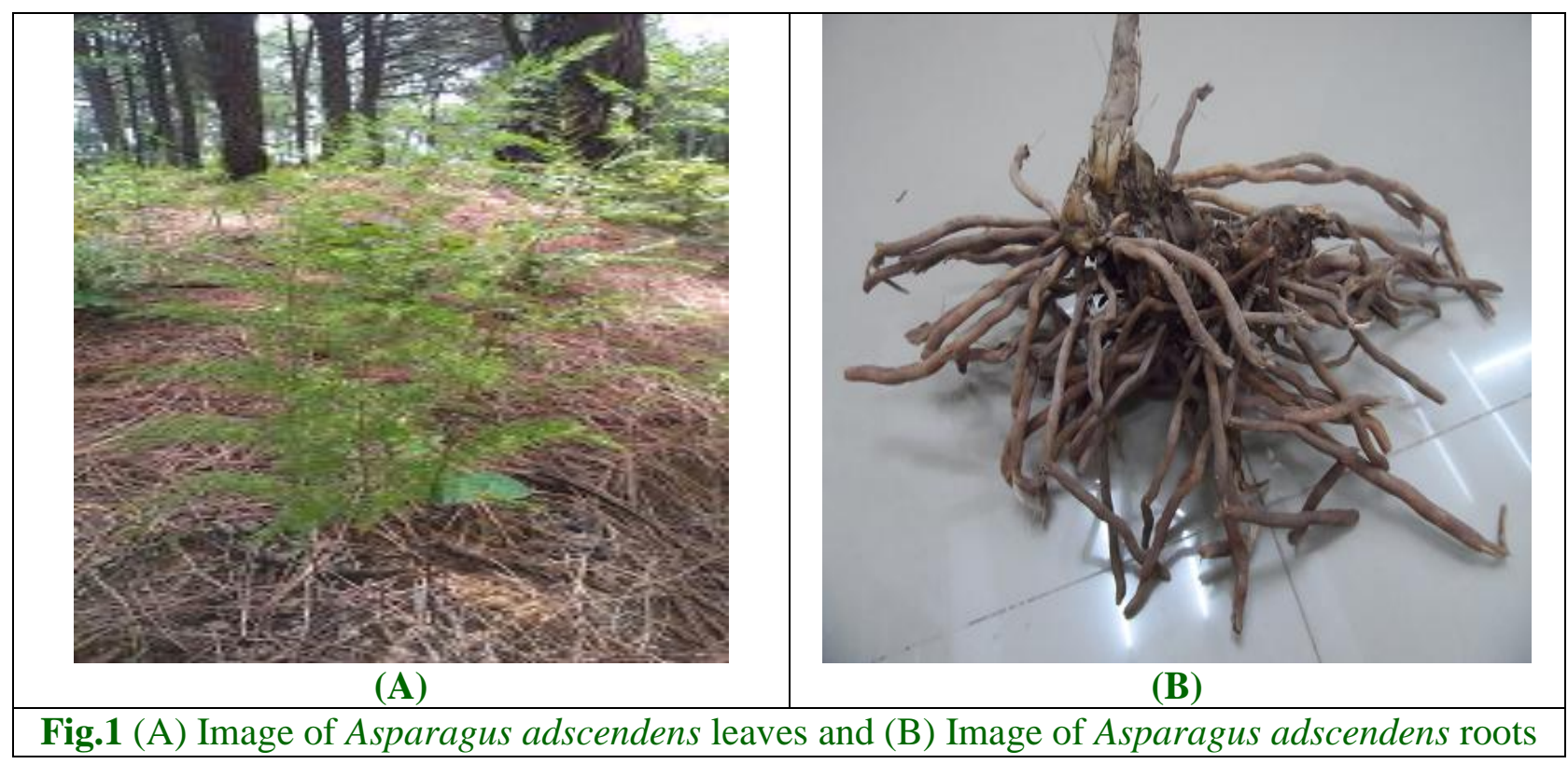



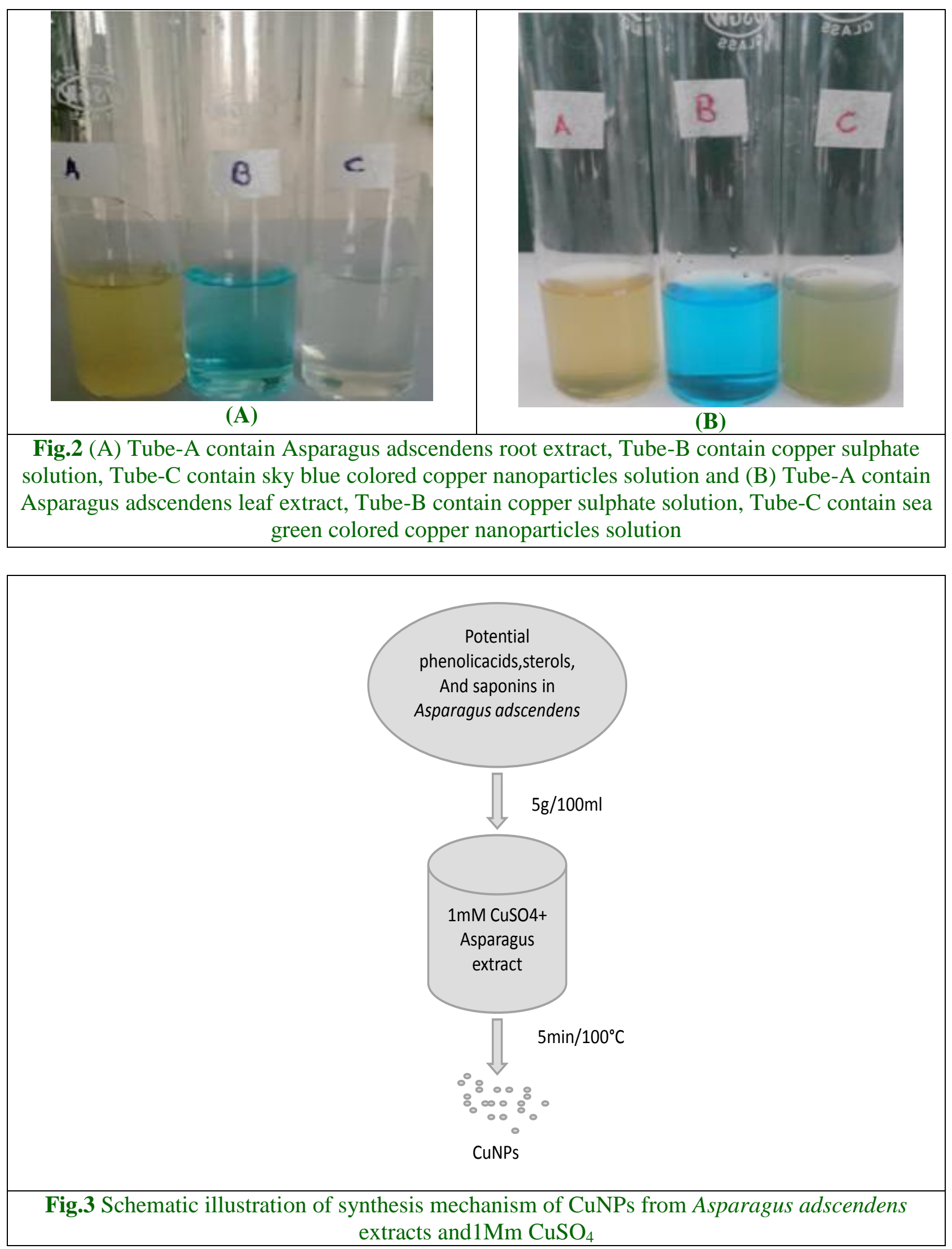

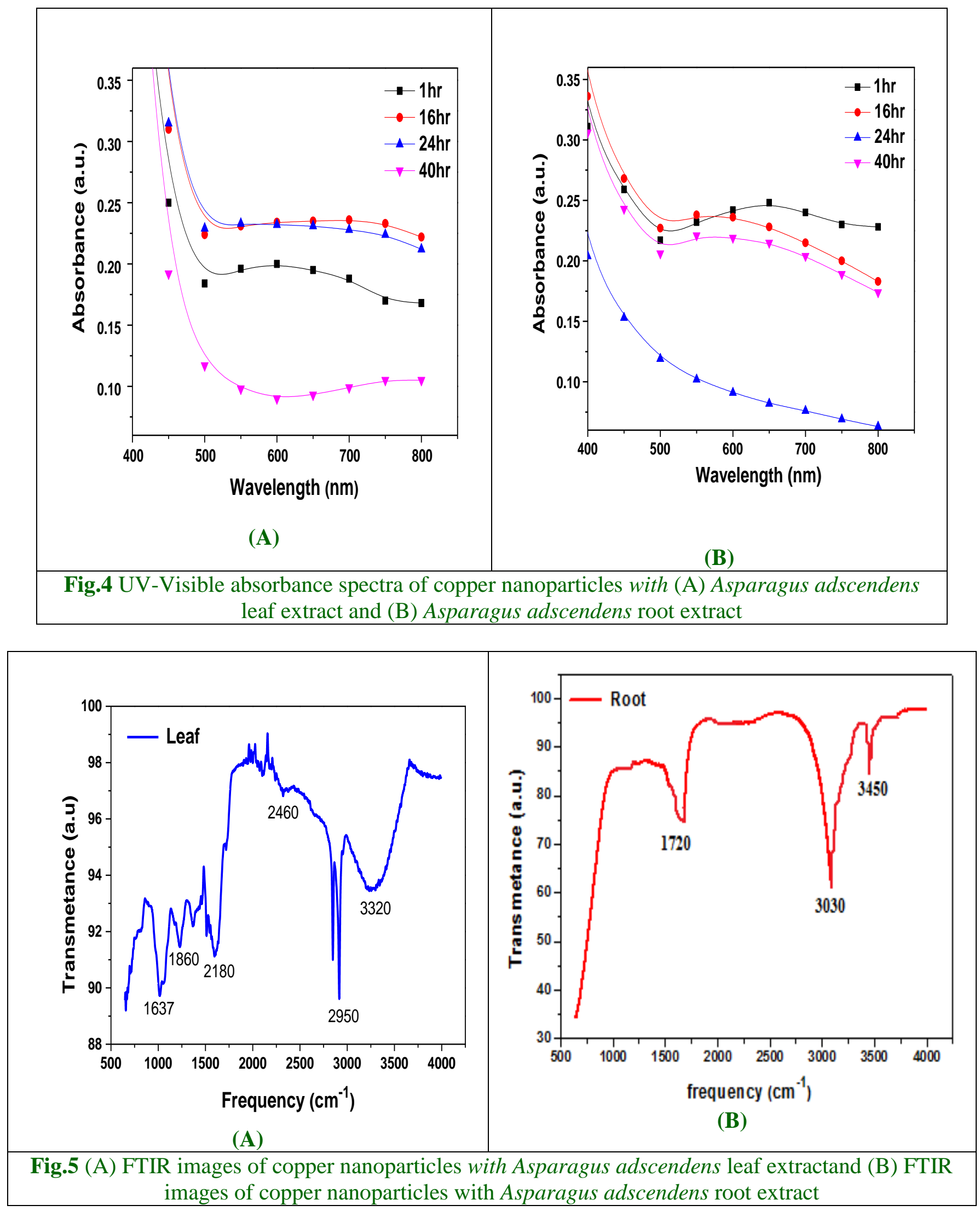


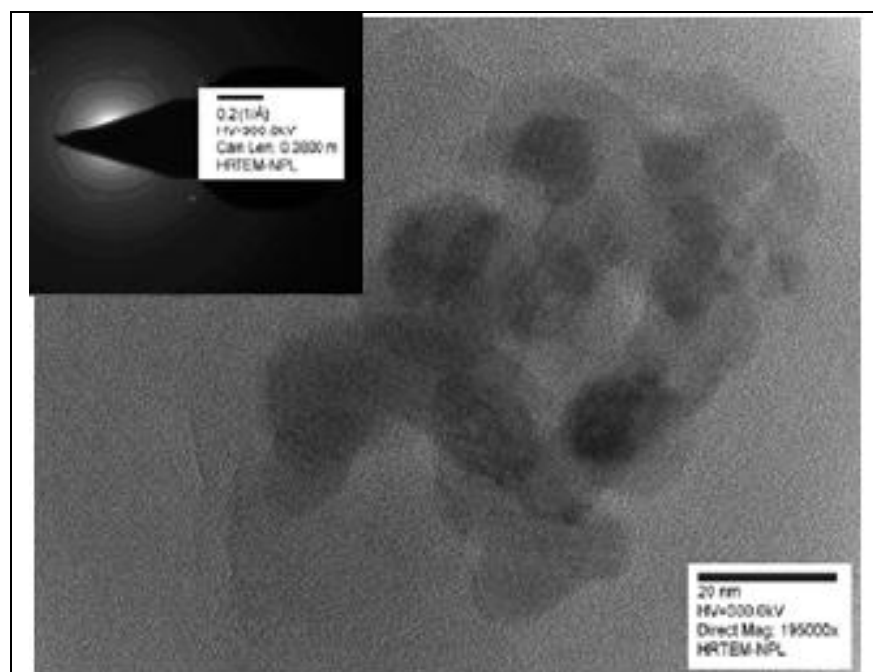

(A)

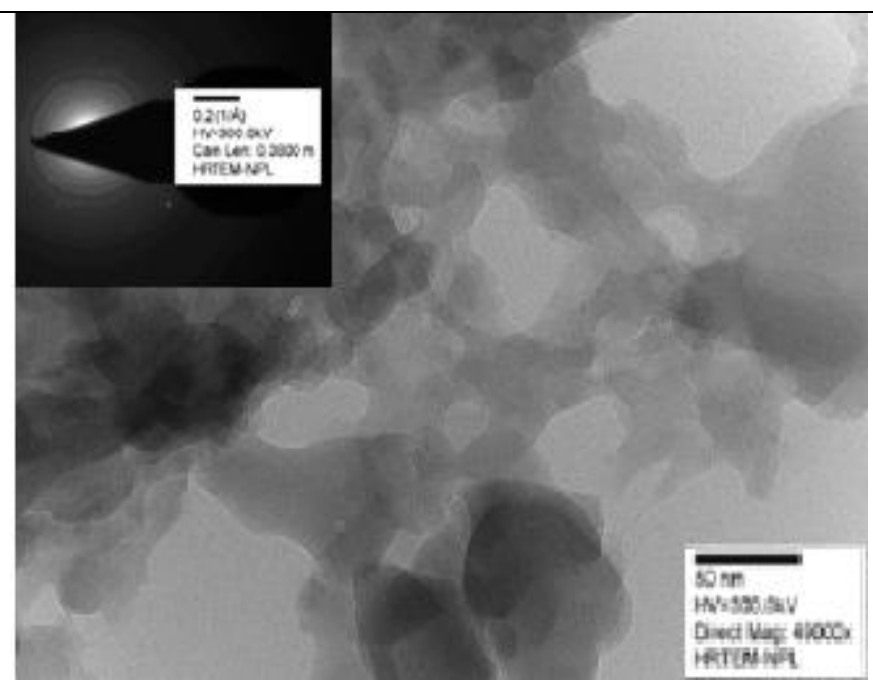

(B)

Fig.6 HRTEM micrograph of the copper nanoparticles synthesized from (A) Asparagus adscendens leaf extract: The scale bar corresponds to $20 \mathrm{~nm}$, (insets: SAED of these metal particles)and (B)Asparagus adscendens root extract: The scale bar corresponds to $50 \mathrm{~nm}$, (insets: SAED of these metal particles)

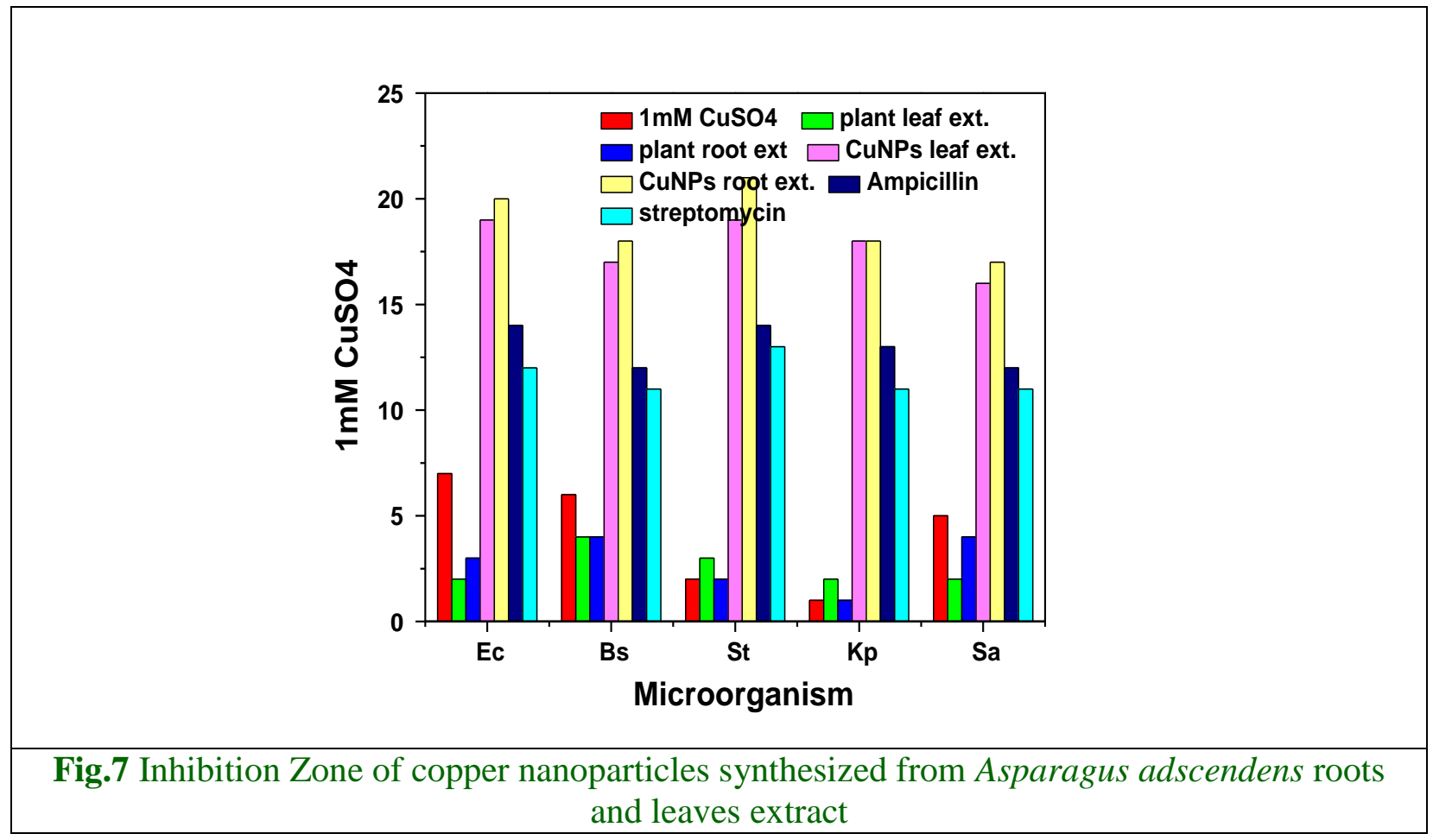

The insets represent the SAED of these metal particles, which reveals the diffusive ring patterns and attributed to the small particle size. The micrograph of biosynthesized copper nanoparticles extract by Asparagus adscendens root display at $50 \mathrm{~nm}$ scale. The particles showed spherical shape and the size ranges from 50 to $60 \mathrm{~nm}$ and uniformly distributed in clusters. The insets represent the SAED of these metal particles, and shows the 
diffusive ring patterns and small particle size. It is known that spherical as well as nonspherical nanoparticles exhibits better physical properties if they are produced small in size, as the antibacterial properties of copper nanoparticles are size dependent.

\section{Antibacterial activity}

The copper nanoparticle synthesized from leaves and root of Asparagus adscendens were subjected to antibacterial activity against Escherichia coli, Bacillus subtilis, Salmonella typhi, Klebsiella pneumonia, and Staphylococcus aureus; both gram- negative and gram- positive bacteria were sensitive to the extracts. In this study, zone of inhibition recorded for various organisms was found; in case of copper nanoparticle synthesized from leaves extract exhibited significant activity against Escherichia coli (19mm), and Salmonella typhi $(19 \mathrm{~mm})$, whereas copper nanoparticle synthesized from root extract have potent antibacterial activity against Salmonella typhi $(21 \mathrm{~mm})$ also. Activity of copper nanoparticle synthesized from roots and leaves of Asparagus adscendens was comparable to that of reference standard drug Ampicillin and Streptomycin $20 \mu \mathrm{g} / \mathrm{ml}$. Copper nanoparticle exhibited good antimicrobial activity and results were tabulated along with figure 7 and Table 2).

It is concluded that the extract of Asparagus adscendens leaves and root are capable of producing copper nanoparticles extracellular and are quite stable in solution. Achievements of such a rapid time scales for the synthesis of copper nanoparticles increases the efficiency of synthetic procedures using environmentally benign natural resources as an alternative to chemical synthesis protocols at low cost. The confirmation of copper nanoparticles synthesis given by colour change of reactions and UV spectra absorption at 500-700 nm range wavelength support the nanoparticles synthesis. Nanoparticles synthesized using many functional groups including amines, alcohols, ketones, aldehydes, alkenes and carboxylic acids present as secondary metabolite in the leaves as well as in the roots of Asparagus adscendens plant. Also it was confirmed that the composite release of copper at a core is capable of rendering antimicrobial efficacy and proved to be active against the Gram negative and Gram positive pathogenic microbes. The present procedure is simple, safe, economic, non-toxic and ecofriendly as compare to toxic chemical process. This study opens up a new opportunity of very conveniently synthesizing copper nanoparticles using natural products which could be useful in various potential applications including drug formulation and biomedical applications in future.

\section{References}

Altman, R.A., Koval, E.D. and Buchwald, S.L., 2007. Copper-catalyzed Narylation of imidazoles and benzimidazoles. The Journal of organic chemistry, 72 (16): 6190-6199.

Baker, S. and Satish, S., 2012. Endophytes: Toward a Vision in Synthesis of Nanoparticle for Future Therapeutic Agents. Int. J. Bio-Inorg. Hybd. Nanomat, 1 (2): 67-77.

Chopra, R.N. and Chopra, I., 2006. Indigenous drugs of India. Academic publishers.

Esteban-Cubillo, A., Pecharromán, C., Aguilar, E., Santarén, J. and Moya, J.S., 2006. Antibacterial activity of copper monodispersed nanoparticles into sepiolite. Journal of materials science, 41 (16): 5208-5212.

Gopalakrishnan, K., Ramesh, C., Ragunathan, V. and Thamilselvan, M., 2012. Antibacterial activity of $\mathrm{Cu}_{2} \mathrm{O}$ nanoparticles on $E$. coli synthesized from Tridax procumbens leaf extract 
and surface coating with polyaniline. Digest J Nanomat Biostruct, 7: 833-839. Grubben, G.J., 2004. Vegetables, 2. Prota.

Ho, J.-Y. and Huang, M.H., 2009. Synthesis of submicrometer-sized $\mathrm{Cu}_{2} \mathrm{O}$ crystals with morphological evolution from cubic to hexapod structures and their comparative photocatalytic activity. The Journal of Physical Chemistry C, 113 (32): 14159-14164.

Huang, H. et al., 1997. Synthesis, characterization, and nonlinear optical properties of copper nanoparticles. Langmuir, 13 (2): 172-175.

Kapoor, S. and Mukherjee, T., 2003. Photochemical formation of copper nanoparticles in poly $(<$ i $>\mathrm{N}</ \mathrm{i}>$ vinylpyrrolidone). Chemical physics letters, 370 (1): 83-87.

Kirtikar, K.R. and Basu, B.D., 1918. Indian Medicinal Plants. Indian Medicinal Plants.

Kuo, C.-H. and Huang, M.H., 2008. Facile synthesis of $\mathrm{Cu}_{2} \mathrm{O}$ nanocrystals with systematic shape evolution from cubic to octahedral structures. The Journal of Physical Chemistry C, 112 (47): 18355 18360.

Kuo, C.H., Chen, C.H. and Huang, M.H., 2007. Seed- Mediated Synthesis of Monodispersed $\mathrm{Cu} 2 \mathrm{O}$ Nanocubes with Five Different Size Ranges from 40 to 420 nm. Advanced Functional Materials, 17 (18): 3773-3780.

Lee, H. et al., 2011. Biological synthesis of copper nanoparticles using plant extract. Nanotechnology, 1 (1): 371-374.

Lisiecki, I. and Pileni, M.P., 1993. Synthesis of copper metallic clusters using reverse micelles as microreactors. Journal of the American Chemical Society, 115 (10): 3887-3896.

McShane, C.M. and Choi, K.-S., 2009. Photocurrent Enhancement of n-Type $\mathrm{Cu} 2 \mathrm{O}$ Electrodes Achieved by Controlling Dendritic Branching
Growth. Journal of the American Chemical Society, 131 (7): 2561-2569.

Panigrahi, S. et al., 2006. Selective one-pot synthesis of copper nanorods under surfactantless condition. Polyhedron, 25 (5): 1263-1269.

Ramgir, N. et al., 2013. Metal oxide nanowires for chemiresistive gas sensors: issues, challenges and prospects. Colloids and Surfaces A: Physicochemical and Engineering Aspects.

Salam, H.A. et al., 2012. Plants: green route for nanoparticle synthesis. Int Res $\mathbf{J}$ Biol Sci, 1 (5): 85-90.

Sapna Thakur, R.R.S.S., 2014. Study the antibacterial activity of copper nanoparticlessynthesized using herbal plants leaf extracts. International Journal of Bio-Technologyand Research (IJBTR), Vol. 4, (Issue 5,): 21-34.

Sharma, S., Chand, R. and Sati, O., 1982. Steroidal saponins of $<$ i $>$ Asparagus adscendens $</ \mathrm{i}>$. Phytochemistry, 21 (8): 2075-2078.

Sharma, S. and Sharma, H., 1984. Oligofuroand spiro-stanosides of $<\mathrm{i}>$ Asparagus adscendens $</ \mathrm{i}>$. Phytochemistry, 23 (3): 645-648.

Song, X., Sun, S., Zhang, W. and Yin, Z., 2004. A method for the synthesis of spherical copper nanoparticles in the organic phase. Journal of colloid and interface science, 273 (2): 463-469.

Subhankari, I. and Nayak, P., 2013. Synthesis of Copper Nanoparticles Using Syzygium aromaticum (Cloves) Aqueous Extract by Using Green Chemistry. World, 2 (1): 14-17.

Tandon, M., Shukla, Y.N. and Thakur, R.S., 1990. Steroid glycosides from $<i>$ Asparagus adscendens $</ \mathrm{i}>$. Phytochemistry, 29 (9): 2957-2959.

Tanori, J. and Pileni, M., 1997. Control of the shape of copper metallic particles by 
using a colloidal system as template. Langmuir, 13 (4): 639-646.

Wagner, H., 1996. Plant drug analysis: a thin layer chromatography atlas. Springer.

White, B. et al., 2006. Complete CO oxidation over $\mathrm{Cu}_{2} \mathrm{O}$ nanoparticles supported on silica gel. Nano letters, 6 (9): 2095-2098.

Wu, S.-H. and Chen, D.-H., 2004. Synthesis of high-concentration $\mathrm{Cu}$ nanoparticles in aqueous CTAB solutions. Journal of colloid and interface science, 273 (1): 165-169.

Xu, H., Wang, W. and Zhu, W., 2006. Shape evolution and size-controllable synthesis of $\mathrm{Cu}_{2} \mathrm{O}$ octahedra and their morphology-dependent photocatalytic properties. The Journal of Physical Chemistry B, 110 (28): 13829-13834.
Yang, Z., Chiang, C.-K. and Chang, H.-T., 2008. Synthesis of fluorescent and photovoltaic $\mathrm{Cu}_{2} \mathrm{O}$ nanocubes. Nanotechnology, 19 (2): 025604.

Yu, H., Yu, J., Liu, S. and Mann, S., 2007. Template-free hydrothermal synthesis of $\mathrm{CuO} / \mathrm{Cu}_{2} \mathrm{O}$ composite hollow microspheres. Chemistry of materials, 19 (17): 4327-4334.

Zhang, H. et al., 2007. One- Pot Synthesis and Hierarchical Assembly of Hollow $\mathrm{Cu}_{2} \mathrm{O}$ Microspheres with NanocrystalsComposed Porous Multishell and Their Gas- Sensing Properties. Advanced Functional Materials, 17 (15): 27662771.

Zhong, C.-J. et al., 2008. Synthesis and Thin Film Assembly of Copper Nanoparticles for Sensing Contaminants in Aircraft Cabins, DTIC Document.

\section{How to cite this article:}

Sapna Thakur, Sushma Sharma, Shweta Thakur and Radheshyam Rai. 2018. Green Synthesis of Copper Nano-Particles Using Asparagus adscendens Roxb. Root and Leaf Extract and Their Antimicrobial Activities. Int.J.Curr.Microbiol.App.Sci. 7(04): 683-694.

doi: https://doi.org/10.20546/ijcmas.2018.704.077 